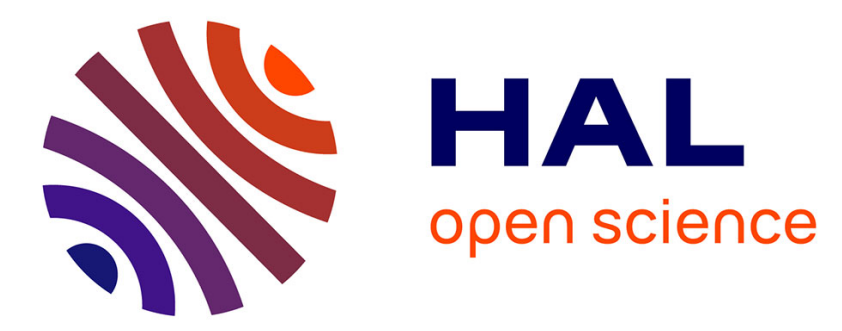

\title{
Crowdfunding with overenthusiastic investors: a global game model
}

\author{
Damien Besancenot, Radu Vranceanu
}

\section{To cite this version:}

Damien Besancenot, Radu Vranceanu. Crowdfunding with overenthusiastic investors: a global game model. 2018. hal-01718793

\section{HAL Id: hal-01718793 \\ https://essec.hal.science/hal-01718793}

Preprint submitted on 27 Feb 2018

HAL is a multi-disciplinary open access archive for the deposit and dissemination of scientific research documents, whether they are published or not. The documents may come from teaching and research institutions in France or abroad, or from public or private research centers.
L'archive ouverte pluridisciplinaire HAL, est destinée au dépôt et à la diffusion de documents scientifiques de niveau recherche, publiés ou non, émanant des établissements d'enseignement et de recherche français ou étrangers, des laboratoires publics ou privés. 


\section{E \\ ESSEC \\ BUSINESS SCHOOL}

\section{CROWDFUNDING WITH OVERENTHUSIASTIC INVESTORS: A GLOBAL GAME MODEL}

RESEARCH CENTER

DAMIEN BESANCENOT, RADU VRANCEANU

ESSEC WORKING PAPER 1802

FEBRUARY 2018 
February 22, 2018

\title{
CROWDFUNDING WITH OVERENTHUSIASTIC INVESTORS: A GLOBAL GAME MODEL
}

\author{
Damien Besancenot*and Radu Vranceanu ${ }^{\dagger}$
}

\begin{abstract}
Crowdfunding platforms are providing funds to an increasing number of projects, among which many have a strong social/community impact. Under a all-or-nothing program, the success of the investment depends on the ability of a crowd of potential investors to put their funds into the project without an explicit coordination device. With heterogeneous information, such a problem can be analyzed as a typical global game. We assume that signals of at least some agents present a systematic positive bias, driven by positive emotions about projects with high social/community impact. The analysis reveals that if the number of such overenthusiastic persons is large enough, crowdfunding finance might support financially inefficient projects. We then analyze how a monopolistic platform optimally determines transaction fees and unveil the relationship between overenthusiasm and the profit of the platform.
\end{abstract}

JEL Classification: I11, G23, G41, D83

Keywords: Crowdfunding, entrepreneurship, global games, overenthusiasm, behavioral IO.

${ }^{*}$ University of Paris Descartes and LIRAES, 45 rue des Saints Pères, 75270 Paris, E-mail: damien.besancenot@parisdescartes.fr.

${ }^{\dagger}$ ESSEC Business School and THEMA, 3 Avenue Bernard Hirsch, 95021 Cergy, France. E-mail: vranceanu@essec.fr. 


\section{Introduction}

In the last decade, the spectacular development of the Internet has created a myriad of new trading opportunities. In particular, advances in information technology have allowed for the emergence of crowdfunding platforms through which a large number of anonymous small investors, spread all over the world, can fund entrepreneurial projects that might not have benefited from traditional financing mechanisms (Agrawal et al., 2014; Mollick, 2014; Belleflamme et al., 2015). In the US, the Obama Administration JOBS Act of 2012 and the subsequent Security and Exchange Commission rules on May 2016 lifted barriers on equity crowdfunding, which provided further momentum to the industry. ${ }^{1} \quad$ In 2016 , there were approximately 200 such Internet funding platforms (André et al., 2017). A number of platforms specialized in start-up equity finance have recently emerged (CrowdFunder, CircleUp) next to the early generalist platforms such as Kickstarter or Indiegogo. Other platforms manage sector-specific projects; for instance MedStartr, Health Tech Hatch, RedCrow will select medical investment projects, and Fundrise and RealtyMogul specialize in real estate projects. Data on the market size of the crowdfunding industry are relatively scarce, but equity crowdfunding, where investors expect a direct financial return from their investment, was estimated at 2.5 billion dollars worldwide in 2015 by Crowdexpert, a consulting company. ${ }^{2}$

The main programs offered by these platforms are of the "all-or-nothing" type: the project will be developed only if the number of contributors who participate to the project allows the entrepreneur to collect a predefined amount of capital that is expected to cover the development cost. Otherwise, the call for funds is closed, and funds are returned to

\footnotetext{
${ }^{1}$ See: SEC Regulation Crowdfunding https://www.sec.gov/rules/final/2015/33-9974.pdf. SEC rules state that "Regulation Crowdfunding, among other things, permits individuals to invest in securities-based crowdfunding transactions subject to certain thresholds, limits the amount of money an issuer can raise under the crowdfunding exemption, requires issuers to disclose certain information about their offers, and creates a regulatory framework for the intermediaries that facilitate the crowdfunding transactions."

${ }^{2}$ See http://crowdexpert.com/ crowdfunding-industry-statistics/
} 
the backers of the project. Thus, the success of the investment depends on the decision of potential investors to put their money into the project without an explicit coordination device. Hence these markets incorporate a "strategic uncertainty" component that goes beyond the classical financial risk. Depending on the project, the investor's return can be participation in future profits, or merely receiving the future product for free or at a discounted price or in advance of commercial distribution. As emphasized by Belleflamme et al. (2015), non-monetary or intrinsic considerations seem to provide an important motivation for crowdfunding investors regardless of the field (see also André et al., 2017). Thus investors' subjective assessment of the final return might be influenced by their positive emotions associated to what they perceive as a meaningful project. Platforms are the first to point out the social impact of these projects. For instance, on their websites, Kickstarter is emphasizing an activity "fully dedicated to building community around creative projects"; Indigegogo will point out a portfolio "loaded with clever and surprising innovations in tech, design, and more"; while MedStartrs openly claims to "inspire patients, physicians, and partners to open their wallets by offering smart, fun, and tangible rewards... that can improve healthcare, make people healthier, and solve problems."3

Crowdfunding platforms have attracted the interest of theoretical economists, who were challenged by the rapid and somehow unexpected development of these extremely decentralized investment markets. Agrawal et al. (2014) provide a survey of the early literature, and emphasize the role of crowdfunding platforms in signaling quality, feedback transmission and trust facilitation. Several recent papers study crowdfunding as a mechanism design problem and reveal when this type of investment might dominate traditional investment mechanisms (inter alia, Grunner et al., 2015; Ellemenas and Hurkens, 2015; Chemla and Tinn, 2016;

\footnotetext{
3 Extraction on 20/11/2017: www.kickstarter.com/ learn?ref=nav; Extraction on 20/11/2017: www.indiegogo.com/about/ what-we-do\#/funding; Extraction on 23/08/2017 at www.medstartr.com /pages/faqs.
} 
Chang, 2016; Strausz, 2017). Belleflame et al. (2014) set up a two-stage model of crowdfunding with pre-orders, assuming that investors would also demand the product, and study the optimal reward scheme. Most of these papers argue that crowdfunding can be an efficient way to finance projects under high demand uncertainty, related to innovative nature of the project. Brown and Davies (2017) analyze investor coordination problem with heterogenous projects and private signals about project quality; their analysis reveals that crowdfunding can bring about large inefficiencies compared to centralized finance, as investors can back bad projects, or avoid backing good projects.

Our paper can be related to the paper by Brown and Davies (2017), given that we also study investors' coordination problem in the highly decentralized crowdfunding market. However, by contrast with them, we frame the decision problem as a typical global game, that we further extend by allowing for a psychological bias in project valuation specific to crowdfunding. Furthermore, as an original contribution, we analyze the optimal decision of a monopolistic platform that can choose the success fee.

In our model, entrepreneurial projects are assumed to emerge sequentially; the return of a given project is a draw from a known statistical distribution. Investors observe the true return of any given project with a bias. In the first part of the paper, we analyze the investor decision problem whether to back the project or not, taking as a given the fee chosen by the platform. In the second part, we explain how a monopolistic platform chooses its fees taking into account the response of investors. As the success of the investment depends on many small investors reaching a predetermined investment target, the investor decision problem can be analyzed as a standard coordination game with strategic complementarity. Under perfect information, these games present multiple equilibria (Diamond and Dybvig, 1993). For instance, in our framework, if all investors participate, the investment target is 
reached, the project is implemented, and each investor will reap a benefit. On the other hand, if all investors choose the risk free asset, an individual who unilaterally deviates and invest in the project earns nothing. Carlson and van Damme (1993) and Morris and Shin $(1998,2001,2004)$ introduced a refinement able to remove the multiplicity of equilibria by making investors' information heterogenous, which provided many applications to capital investment (for a survey, see Jorge and Rocha, 2015 or Angeletos and Rian, 2016). They show that if each investor receives a biased idiosyncratic signal about the true financial performance of the project, investors' beliefs are no longer common knowledge, and the game presents a "threshold equilibrium" characterized by a critical signal above which an investor will participate in the risky project. In equilibrium, this critical signal is determined in conjunction with a cut-off return that ensures the participation of a sufficient mass of investors such as the project can implement.

We extend the traditional global game analysis to allow for a subset of the population of potential investors to have an overenthusiastic evaluation of the future financial returns of the project. This bias is backed by their positive emotions activated by investing in a "good", socially impactful project. Our modelling assumption is grounded in an extensive literature in psychology and experimental economics, which revealed that, depending on the context, human beings may develop systematic perception and self-perception biases. As an example, a substantial body of literature in corporate finance shows that CEOs tend to overestimate returns from their investments (Malmendier and Tate, 2005), a miscalculation stemming from their overconfidence in their own skills. Bénabou and Tirole $(2002,2016)$ acknowledge that such belief distortion cannot be discarded by economic analysis, and provide a theoretical framework for understanding these departures from strict rationality. Armstong and Spiegler (2007) and Grubb (2015) survey the substantial literature that emphasizes cognitive biases 
and bounded rationality in consumer choices. In the realm of crowdfunding, Agrawal et al. (2014) point out that "founders and creators are initially overoptimistic about outcomes", and present cases where investors revised downward their expectations when some artists failed to deliver on their musical projects. Davis et al. (2017) analyze the psychological mechanism through which a project pitch perceived as creative fosters chances that the individual will support the project.

Our analysis shows that the presence of these overenthusiastic agents raises the number of participants in the project and the chances that the project is implemented. We reach a similar conclusion as Brown and Davis (2017) in showing that some of the successful projects might be financially inefficient even if the uncertainty surrounding the project is small, thus bringing a net return that is inferior to the return on the risk free asset. Furthermore, the scope for such inefficiency broadens if the number of overenthusiastic agents increases. In the second part, the analysis reveals a non-monotonic relationship between the success fee charged by the platform and the ex-ante expected profit; we can determine the optimal fee chosen by a monopolistic platform. We further study how the maximum expected profit is related to the frequency of overenthusiastic agents.

The paper is organized as follows. The next section introduces the main assumptions of the model. Section 3 solves the investor decision game for the threshold equilibrium. The properties of the solution are analyzed in section 4. In Section 5, we analyze the optimal choice of the fee by the platform. The last section concludes.

\section{Main assumptions}

We study the interaction between the crowdfunding platform and a large group of investors. The supply of entrepreneurial projects is assumed to be exogenous.

At each time period, a new investment project becomes available. Depending on the 
funding agreement, the return can be participation in the future profit, or the market value of the product if the investor agrees to receive the product as a reward. The actual return $\theta$, to be achieved after the development and commercialization of the product, is a random variable that acknowledges the multiple risks associated with such projects (technological, demand, regulatory). More specifically, we assume that the distribution of net returns is uniform on the support $[0, Z]$, with $Z$ large, $\theta \rightsquigarrow$ unif $[0, Z] .{ }^{4}$ This distribution is common knowledge and will capture the classical financial risk.

There is a continuum $[0, M]$ of potential investors, each being endowed with 1 dollar of savings. They can invest their funds in a risk free asset or invest them in a risky project with the same duration of investment as the risk free asset. To keep the analysis simple, we consider that individuals are risk neutral. Let $L$ denote the number of investors who decide to participate in the entrepreneurial project. The project implies a known development cost $V$. If enough investors participate $(L \geq V)$, they can cover the development cost and the project is implemented; otherwise $(L<V)$, the project fails and investors recover their initial funds. To simplify notation, we normalize the mass of investors to 1 and denote by $l=L / M$ the number of investors and denote by $v=V / M$ the investment target. Then the success condition of the project is merely:

$$
l \geq v .
$$

In general crowdfunding platforms are for-profit organizations. In all-or-nothing campaigns, they charge a fee per dollar invested if the investment target $v$ is met. This success fee is determined by the platform at the outset of the game and is taken as given by investors. ${ }^{5}$ Let $\rho$ denote the success fee.

\footnotetext{
4 This assumption allows us to provide explicit solutions. With normally distributed returns the model can be solved for a graphic solution.

${ }^{5}$ For instance, Kickstarter will charge $5 \%$ of the collected funds, Medstart charges $6 \%$. Some transfer charges can also be included.
} 
Thus, the net return of an investor contingent upon his/her decision and the decision of the other investors is:

$$
\left\{\begin{array}{l}
\text { invest in the entrepreneurial project: }\left\{\begin{array}{l}
(\theta-\rho), \text { if } l \geq v \\
0 \text { if } l<v
\end{array}\right. \\
\text { invest in the safe asset: } r
\end{array}\right.
$$

Following the standard approach in the global games literature, we assume that when a new project becomes available, each investor makes his subjective evaluation of its potential return, based on his/her own reading of the project, which can differ from the "true" return. As an original development of this paper, we further consider that the set of potential investors comprises two distinct types of players:

- There are $(1-\gamma)$ "rational agents" who consider the project with a "cold heart" as an ordinary financial investment project. In this subset, each investor $i$ has a personal measure $x_{i}$ of the project value: $x_{i}=\theta+\varepsilon_{i}$, with $\varepsilon_{i} \rightsquigarrow$ unif $[-\epsilon, \epsilon]$ and $\epsilon>0$. In this first group, even if the assessment of the project is imperfect, investors have a globally unbiased evaluation of its return. ${ }^{6}$

- The remaining $\gamma$ investors are "overenthusiastic". An overenthusiastic investor has a systematic positive bias in the assessment of the returns related to the very nature of the entrepreneurial project. In contrast with the rational investor, his/her signals are: $x_{i}=$ $\theta+\varepsilon_{i}+\mu$, where $\varepsilon_{i} \in[-\epsilon, \epsilon]$ and $\mu>0$. As explained in the introduction, the bias $\mu$ stems from the positive emotions related to an investment in a product with a social dimension, a feeling of "doing good" specific to some humans.

However, we assume that overenthusiastic agents are not aware of their bias; otherwise, they would correct it. Overconfident CEOs do not consider themselves overconfident, and they would not agree that they tend to exaggerate potential returns compared to the bench-

\footnotetext{
${ }^{6}$ This assumption is at the heart of all existing global games.
} 
mark group of CEOs. In the case of crowdfunding investment let's say in arts or the medical sector, those who provide an enthusiastic assessment do not consider themselves enthusiastic, they just do what they have to do. They therefore use the same decision rule as the rational agents.

Regardless of their type, all investors are aware of the presence of overenthusiastic investors as a general characteristic of the market. More specifically, they all know the nature of the assessment bias and the distribution of overenthusiastic investors in the population. Let us denote by $l_{R}$ (respectively $l_{O}$ ) the frequency of rational (respectively overenthusiastic) investors who decide to participate in the risky project.

The success condition (1) becomes:

$$
l=(1-\gamma) l_{R}+\gamma l_{O} \geq v
$$

In the following, the amount of overenthusiasm defined by the product $\omega=\gamma \mu$ plays an important role in the analysis; we will refer to $\gamma$ as the extensive margin of overenthusiasm and to $\mu$ as the intensive margin.

As an upshot of these, the decision timeline is:

\begin{tabular}{lllll}
\hline$t=0$ & $t=1$ & $t=2$ & $t=3$ & $t=4$ \\
\hline Platform & Project emerges & Investor $i$ & Investors: & Project: \\
sets $\rho$ & $\theta \in[0, Z]$ & observes $x_{i}$ & invest/wait & succeeds/fails \\
\hline \multicolumn{4}{c}{ Decision Timeline }
\end{tabular}

\section{The equilibrium of the investment game}

Morris and Shin $(1998,2001,2004)$ have shown that such $n$-person coordination games with heterogeneous information present a "threshold equilibrium" in which all investors receiving a signal above a critical value $x^{*}$ invest and all those who receive a signal below $x^{*}$ refrain 
from investing in the risky project. Connected to this critical signal, there is a cut-off "state variable" $\theta^{*}$ characteristic of the payoff of the successful project above which the project succeeds, and below which the project fails. We follow the now standard resolution steps (Atkeson, 2001; Veldkamp, 2011) and directly determine the two critical thresholds $\left(x^{*}, \theta^{*}\right)$.

1. The cut-off profit $\theta^{*}$, taking as given the critical signal $x^{*}$.

When a project with performance $\theta$ is made available on the platform, rational investors observe signals $x_{R_{i}}$ in the interval $[(\theta-\epsilon),(\theta+\epsilon)]$, and overenthusiastic ones observe signals $x_{O i}$ in the interval $[(\theta-\epsilon+\mu),(\theta+\epsilon+\mu)]$. Because agents do not know to what type they belong, they use the same decision rule. More precisely, they have the same critical signal $x^{*}$ regardless of their type. The frequency of individuals who invest is given by:

$$
\begin{aligned}
& l_{R}=\operatorname{Pr}\left[x_{R_{i}}>x^{*} \mid \theta\right]=\frac{1}{2 \epsilon}\left(\theta+\epsilon-x^{*}\right) \\
& l_{O}=\operatorname{Pr}\left[x_{O i}>x^{*} \mid \theta\right]=\frac{1}{2 \epsilon}\left(\theta+\epsilon+\mu-x^{*}\right)
\end{aligned}
$$

Note that both $l_{R}$ and $l_{O}$ are increasing with $\theta$. The total number of investors is obtained replacing the explicit expressions of $l_{R}$ and $l_{O}$ in Eq. (2).

$$
l=\frac{1}{2 \epsilon}\left(\theta+\epsilon-x^{*}\right)+\frac{1}{2 \epsilon} \omega .
$$

The presence of overenthusiastic agents increases the number of investors beyond what we would expect with only rational agents and makes it easier to reach the target $v$. For a given critical signal $x^{*}$, there is a cut-off return $\theta=\theta^{*}$ for which the number of investors is sufficient to cover the development cost. This cut-off return is implicitly defined by $l=v$ or:

$$
\left(x^{*}-\theta^{*}\right)=\omega+\epsilon(1-2 v)
$$

This is the first key equation of the game.

2. The critical signal $x^{*}$ taking as given the cutoff profit . 
The observation of the signal allows investors to update their beliefs about the distribution of returns. Any player $i$ who receives a signal $x_{i}$ believes that $\theta$ is uniformly distributed in the interval $\left[\left(x_{i}-\epsilon\right),\left(x_{i}+\epsilon\right)\right] .^{7}$

In the continuum of investors, there should be a player who is indifferent between investing in the risk free project or in the risky entrepreneurial project. We have denoted his/her signal by $x^{*}$. To determine $x^{*}$, we set the indifference condition:

$$
\int_{\theta^{*}}^{\left(x^{*}+\epsilon\right)}(\theta-\rho) d F\left(\theta \mid x^{*}\right)=r
$$

where the left-hand term indicates the expected net return if the investor chooses the risky project, based on the conditional distribution of $\theta \rightsquigarrow\left[\left(x^{*}-\epsilon\right),\left(x^{*}+\epsilon\right)\right]$. For $\theta>\theta^{*}$, the project succeeds and brings to investors $(\theta-\rho)$. For $\theta<\theta^{*}$ the project fails. With our uniform distribution, the former condition becomes:

$$
\begin{aligned}
\frac{1}{2 \epsilon} \int_{\theta^{*}}^{\left(x^{*}+\epsilon\right)}(\theta-\rho) d \theta & =r \\
\frac{1}{2 \epsilon}\left\{\left[\frac{\theta^{2}}{2}\right]_{\theta^{*}}^{\left(x^{*}+\epsilon\right)}-[\rho \theta]_{\theta^{*}}^{\left(x^{*}+\epsilon\right)}\right\} & =r \\
{\left[\left(x^{*}+\epsilon\right)-\theta^{*}\right]\left[\left(x^{*}+\epsilon\right)+\theta^{*}-2 \rho\right] } & =4 \epsilon r
\end{aligned}
$$

This is the second key equation of the global game.

The solution of the game is the couple $\left(\theta^{*}, x^{*}\right)$ that simultaneously fulfills equations $(6)$ and (8):

$$
\begin{aligned}
& x^{*}=\frac{2 \epsilon r}{[\omega+2 \epsilon(1-v)]}+\rho+0.5 \omega-\epsilon v \\
& \theta^{*}=\frac{2 \epsilon r}{[\omega+2 \epsilon(1-v)]}+\rho-0.5 \omega-\epsilon(1-v)
\end{aligned}
$$

Note that all projects with $\theta>\theta^{*}$ will be implemented. Thus the frequency of successful projects is: $f=1-\left(\theta^{*} / Z\right)$.

\footnotetext{
7 Recall that overenthusiastic players are not aware of their psychological bias, so they have the same updating rule as the rational ones.
} 


\section{Properties of the solution}

\subsection{Changes in parameters}

In line with intuitive reasoning, the cut-off return $\theta^{*}$ is increasing in $v, \rho$, and $r$ and is decreasing in $\omega$. The higher the critical number of investors requested for the project to succeed $v$, the higher the strategic risk; in this case investors will participate only if the project delivers high returns. If the fee $(\rho)$ required by the platform is too high, the investor benefit is eroded, and only a high return would prompt them to come back. When risk free investments provide higher returns $(r)$, a risky project must present a higher profitability in order to be attractive. Finally, the higher the intensive $(\gamma)$ and the extensive $(\mu)$ margins of overenthusiasm, the higher the participation in the project, which makes more projects appealing, including those with lower returns.

The relationship between $\theta^{*}$ and the amount of signal noise $(\epsilon)$ is non-linear. Indeed, the derivative

$$
\frac{d \theta^{*}}{d \epsilon}=\frac{2 r \omega}{[\omega+2 \epsilon(1-v)]^{2}}-(1-v)
$$

is negative if the noise is high enough, and vice versa.

$$
\frac{d \theta^{*}}{d \epsilon}<0 \Leftrightarrow \epsilon>\frac{1}{2(1-v)}\left[\sqrt{\frac{2 r \omega}{(1-v)}}-\omega\right]
$$

We remark that this condition is always fulfilled if the amount of overoptimism is small enough, more precisely if $\omega<\frac{(1-v)}{2 r} \Leftrightarrow \sqrt{\frac{2 r \omega}{(1-v)}}-\omega<0$.

\subsection{Financial efficiency analysis}

We know that all projects with $\theta>\theta^{*}$ will attract enough investors to be implemented. If $\theta^{*}<(\rho+r)$, then, among all the successful projects $\left(\theta>\theta^{*}\right)$, we can find financially inefficient projects, characterized by $\theta<(\rho+r)$. Indeed, these projects will pay a net return lower than the risk free rate of return. 
The general condition indicating when some financially inefficient projects might be implemented is thus $\theta^{*}<(\rho+r) \Leftrightarrow\left(\theta^{*}-\rho\right)<r$. It can be shown that both the signal noise and the amount of overenthusiasm contribute to this outcome.

As shown in the Appendix, the former condition is equivalent to:

$$
H=[\omega+2 \epsilon(1-v)]^{2}-2 r(2 \epsilon v-\omega)>0 \text { with } \omega>0 .
$$

The function $H=H(\omega)$ is a convex parable. Calculations (also in the Appendix) show that the roots of $H(\omega)=0$ are:

$$
\omega_{1,2}=-[2 \epsilon(1-v)+r] \pm \sqrt{4 r \epsilon+r^{2}}
$$

The function takes positive values for $\omega<\omega_{1}$ and $\omega>\omega_{2}$,

Obviously, for $\epsilon>0$ we have $\omega_{1} \leq 0$. Thus condition (13) is fulfilled for:

$$
\omega>\omega_{2}=-[2 \epsilon(1-v)+r]+\sqrt{4 r \epsilon+r^{2}}
$$

Denoting by $\epsilon_{0}=\frac{r v}{[(1-v)]^{2}}$, we can check that $\omega_{2}>0$ for $0<\epsilon<\epsilon_{0}$ and $\omega_{2}<0$ for $\epsilon>\epsilon_{0}$.

Proposition 1 If the noise of the signal is large $\left(\epsilon>\epsilon_{0}\right)$, inefficient projects may be implemented regardless of the number of overenthusiastic agents.

Proof. For a large noise, $\epsilon>\epsilon_{0}$, the larger root of $H(\omega)=0$ is negative, $\omega_{2}<0$. Thus $H(\omega)>0, \forall \omega>0$ which is equivalent to $\left(\theta^{*}-\rho\right)<r$.

Proposition 2 If the noise of the signal is small $\left(\epsilon<\epsilon_{0}\right)$, yet the number of overenthusiastic agents is relatively large $\left(\omega>\omega_{2}\right)$, then inefficient projects may be implemented.

Proof. For a small noise, $\epsilon<\epsilon_{0}$, the larger root of $H(\omega)=0$ is positive, $\omega_{2}>0$. Then, for $\omega>\omega_{2} \Leftrightarrow H(\omega)>0 \Leftrightarrow\left(\theta^{*}-\rho\right)<r$

Corollary 3 If the noise of the signal is small $\left(\epsilon<\epsilon_{0}\right)$ and overenthousiasm is limited $\left(\omega<\omega_{2}\right)$, then all implemented projects are financially efficient. 
As an upshot of these, a large noise or a large number of overenthusiastic agents raise the chances that inefficient projects might be implemented. In a standard global game with strictly rational agents, a small noise would suffice to ensure financial efficiency, an outcome that is challenged by the presence overenthusiastic agents.

\section{The optimal fee of the platform}

So far, we have studied investors' decision given the fee decided by the platform at the outset of the game. In this section, we analyze how the platform chooses the optimal fee, taking into account the second-stage response of investors.

To keep the analysis as simple as possible, we assume that the platform is the only provider of crowdfunding services. Its goal is to maximize its profits. There is a fixed operating cost, which we can normalize to zero without loss of generality. Then the total profit for the platform is merely the fee times the number of investors.

Then, the profit-maximizing platform faces a dilemma: If it increases the success fee $\rho$, all things equal, it would earn more per each dollar invested. However, because a higher fee pushes up the equilibrium signal $x^{*}$, less investors will participate in each project, and less projects will be successful, as $\theta^{*}$ also increases. For a very large fee, the expected profit must be zero. A similar trade-off has been emphasized by Peia and Vranceanu (2017) in a global game model of infrastructure project finance, where fee-maximizing financial itermediaries must post an optimal interest rate.

Formally, for any given $\theta \in[0, Z]$, the frequency of investors $l\left(\theta, x^{*}(\rho)\right)$ is given by equation (5), evaluated for the equilibrium critical signal $x^{*}=x^{*}(\rho)$ as defined in equation (9).

The platform must choose and post $\rho$ before $\theta$ is realized. It therefore decide on $\rho$ based on the ex-ante expected profit, and this expectation must take into account the whole 
distribution of future returns. Formally, the expression of the expected profit is:

$$
\Pi=\rho \int_{\theta^{*}(\rho)}^{Z} l\left(\theta, x^{*}(\rho)\right) d F(\theta),
$$

an expression in which we acknowledge that the platform can charge the fee only if the project is successful, i.e. for $\theta>\theta^{*}(\rho)$.

After substituting $l\left(\theta, x^{*}(\rho)\right), x^{*}(\rho)$ and $\theta^{*}(\rho)$ by their explicit forms, calculations in the Appendix allow us to write the expected profit as a function of the fee $\rho$ :

$$
\Pi(\rho)=(2 Z \epsilon)^{-1} \rho[0.5(a-\rho)+2 \epsilon v](a-\rho) .
$$

where we denoted by $a=Z-\frac{2 \epsilon r}{[\omega+2 \epsilon(1-v)]}+0.5 \omega+\epsilon(1-v)>0$ or $\left(Z-\theta^{*}\right)=(a-\rho)$.

The function $\Pi(\rho)$ is a standard polynomial of third degree with three solutions: $\rho_{1}=0$, $\rho_{2}=a, \rho_{3}=a+4 \epsilon v$, which can be ordered $\rho_{1}<\rho_{2}<\rho_{3}$.

Obviously our problem is defined only for parameter values that ensure that $\theta^{*}<Z \Leftrightarrow$ $\rho<\rho_{2}=a$. In the opposite case where $\rho>\rho_{2}$, then $\theta^{*}>Z$, no project will ever be implemented, the market does not exist.

We remark that for $\rho<a$ the expected profit is positive.

Proposition 4 There is an optimal fee, $\hat{\rho}$, which maximizes the ex-ante expected profit of the platform, with $\hat{\rho} \in\left[0, \rho_{2}\right]$.

Proof. The problem is defined for $\rho \in\left[0, \rho_{2}\right]$. Calculations in the appendix show that $[d \Pi / d \rho]_{\rho=0}>0$. Also, we know that $\Pi(0)=\Pi\left(\rho_{2}\right)=0$. Then the function $\Pi(\rho)$ presents a maximum in the interval $\left[0, \rho_{2}\right]$. The first order condition $d \Pi / d \rho=0$ defines the optimal fee (see Appendix) as:

$$
\hat{\rho}=\frac{2}{3}\left[(a+2 \epsilon v)-\sqrt{(0.5 a+2 \epsilon v)^{2}-\epsilon v a}\right] .
$$

We can check that $\hat{\rho}<\rho_{2}$. 
As we mentioned, the presence of overenthusiastic investors seem to be an important distinguishing characteristic of crowdfunding investment. It is interesting to study the impact of this psychological bias on the platform decision.

Proposition 5 The optimal fee is increasing in the number of overenthusiastic agents.

Proof. See Appendix for the calculation of the derivative $d \hat{\rho} / d \omega>0$

Which leads us to our last result:

Proposition 6 The maximum expected profit is increasing in the number of overenthusiastic agents

Proof. The maximum expected profit is the product of $\hat{\rho},(a-\hat{\rho})$, and $0.5(a-\hat{\rho})+2 \epsilon v$. We know $d \hat{\rho} / d \omega>0$. Next, $(a-\hat{\rho})$ is an increasing function in $a$, and $d a / d \omega>0$, thus $d(a-\hat{\rho}) / d \omega>0$. The maximum expected profit is increasing in $\omega$.

This result suggests that a monopolistic crowdfunding platform might have an interest to over-emphasize the "moral" dimension of the project. This strategic communication would push up the amount of overenthusiasm and ensure higher fees and higher profits.

\section{Conclusion}

In the last few years equity crowdfunding has become an important mechanism for financing entrepreneurial projects with a strong social and comunity-oriented dimension. A multitude of internet platforms emerged to match projects with investors. Most of them will run all-ornothing schemes, where funds are transferred to entrepreneurs only if a predetermined and justified investment target is fulfilled. This paper introduces an analysis of the crowdfunding market that emphasizes the coordination frictions specific to all-or-nothing financing schemes. In a first step, we analyzed investors decisions, taking as given the fee chosen by the platform. In a second step, we analyze how a monopolistic platform chooses the optimal fee. 
Because investors are small and anonymous, the success of the projects relies on their ability to coordinate on the "invest" decision. In this paper, we use the global games refinement introduced by Van Damme (1993) and Morris and Shin $(1998,2001)$ to solve the model for the "threshold equilibrium", characterized by a critical signal and a cut-off return. As as specific feature of crowdfunding investment, we allowed for some agents to develop a positive and insidious perception bias, grounded in positive emotions activated by the investment in a meaningful product. Such affect backed bounded rationality can be at work in various crowdfunding projects (Agrawal et al., 2014; Belleflamme et al., 2014; Davis et al., 2017).

Most often, crowdfunding platforms claim to reduce project risk through a careful selection of the best projects by qualified experts. At the same time, they will communicate extensively on the social impact of the project. Our model shows that, by contrast with the insights of a classical global game with strictly rational agents, in the presence of overenthusiastic agents that present a positive perception bias, financially inefficient projects can be implemented even if the precision of the signal is large. Thus, reducing the noise of the signal by expert screening might be offset by an investment behavior guided by positive feelings about the nature of the investment project, which would ultimately lead to implementation of financially inefficient projects and deceive investors.

As an original contribution to the crowdfunding literature, we show that the relationship between the fee chosen by a monopolistic platform and the expected profit is non-linear and solve the problem for the profit maximizing fee. This fee is an increasing function in the number of overenthusiastic agents and so is the expected profit of the platform, despite the negative effect of the higher fee on the total number of investors. This might explain the tendency of existing platforms to over-communicate on the social impact of the product and also might explain why many projects might fail to deliver on their high promises. 
In our paper, entrepreneurs were assumed to be honest, and made the best use of the transferred resource. Yet crowdfunding markets lack the transparency, reputation building and monitoring specific to traditional finance, which can ultimately generate fraud and deception, something that our analysis did not explicitly take into account. Another limitation, in our model, investors make their decisions simultaneously. The outcome of the game is dichotomous; the project is either implemented or fails, depending on its return. In practice platforms keep a time-window of investment open and inform investors about the percentage of achievement of the investment target in real time. Thus, latecomers know how many investors have already committed to the project. Our model could be modified to a two-stage investment game, where the key decisions belong to the second stage investors. ${ }^{8}$ However, the investment problem of these second-period investors is not be fundamentally different from the problem studied in a one-stage game.

Despite its limitations, our simple model can be seen as a first step in understanding the coordination challenge implicit in crowdfunding investing and how this strategic uncertainty affects the chances that the project is implemented. Our analysis corroborates the findings by Brown and Davies (2016), in pointing out that crowdfunding is not a guarantee for financial efficiency and thus should not be seen as a natural substitute for traditional forms of project finance. Finally, platform market power could increase these inefficiencies, which calls for increased competition in this market and a close monitoring of excessive profits by antitrust authorities.

\section{References}

Agrawal, A., C. Catalini and A. Goldfarb, 2014. Some simple economics of crowdfunding, Innovation Policy and the Economy 14, 1: 63-97.

\footnotetext{
8 Angeletos et al. (2007) introduced a dynamic global game with learning about the distribution of errors, which presents multiple or single equilibria depending on the amount of uncertainty.
} 
André, K., S. Bureau, A. Gautier, and O. Rubel, 2017, Beyond the opposition between altruism and self-interest: Reciprocal giving in reward-based crowdfuning, Journal of Business Ethics, 146: 313-332.

Angeletos, G. -M. and C. Lian, 2016. Incomplete information in macroeconomics: Accommodating frictions in coordination. Handbook of Macroeconomics, 2: 1065-1240.

Angeletos, G. M., Hellwig, C. and A. Pavan, 2007. Dynamic global games of regime change: Learning, multiplicity, and the timing of attacks. Econometrica, 75, 3: 711-756.

Armstrong, M., and R. Spiegler, 2007. Boundedly rational consumers: Outline of a survey. University College London, mimeo.

Atkeson, A. A., 2001. Comment on Morris and Shin: Rethinking multiple equilibria in macroeconomic modeling, NBER Macroeconomics Annual 2000, 15: 162-171.

Belleflamme, P., Omrani, N. and M. Peitz. 2015. The economics of crowdfunding platforms. Information Economics and Policy 33: 11-28.

Belleflamme, P., Lambert T. and A. Schwienbacher, 2014. Crowdfunding: Tapping the right crowd, Journal of Business Venturing 29, 5: 585-609.

Bénabou, R. and J. Tirole, 2016. Mindful economics: The production, consumption, and value of beliefs. Journal of Economic Perspectives, 30, 3: 141-164.

Bénabou, R. and J. Tirole, 2002. Self-confidence and personal motivation. Quarterly Journal of Economics 117, 3: 871-915.

Brown, D. C., and S. W. Davies, 2016, Equity crowdfunding: Harnessing the wisdom of the crowd, SSRN Electronic Journal, 10.2139/ssrn.2692828.

Carlsson, H. and E. Van Damme, 1993. Global games and equilibrium selection, Econometrica, 61 5: 989-1018.

Chang, Jen-Wen, 2016, The economics of crowdfunding, Available at SSRN: https://ssrn.com/abstract $=2827354$

Chemla G. and K. Tinn, 2016, Learning through crowdfunding, CEPR Discussion Paper 11363.

Davis, B. C., Hmieleski, K. M., Webb, J. W., and Coombs, J. E., 2017. Funders' positive affective reactions to entrepreneurs' crowdfunding pitches: The influence of perceived product creativity and entrepreneurial passion. Journal of Business Venturing, 32, 1: $90-106$.

Diamond, D. W., and P. H. Dybvig, 1983. Bank runs, deposit insurance, and liquidity. Journal of Political Economy 91, 3: 401-419.

Ellman, M., and S. Hurkens, 2015. Optimal crowdfunding design, Barcelona GSE Working Paper 871.

Grubb, M. D., 2015, Behavioral consumers in industrial organization: An overview, Review of Industrial Organization 47, 3: 247-258. 
Grüner, H. P. and C. Siemroth, 2015. Cutting out the middleman: Crowdinvesting, efficiency, and inequality. Mimeo, University of Manheim.

Jorge J. and J. Rocha, 2015. A primer on global games applied to macroeconomics and finance, Journal of Economic Surveys 29, 5: 869-886

Malmendier, U. and G. Tate, 2005. CEO overconfidence and corporate investment. The Journal of Finance 60, 6: 2661-2700.

Morris, S. and H. S. Shin, 1998. Unique equilibrium in a model of self-fulfilling currency attacks, American Economic Review 88, 3: 587-597.

Morris, S. and H. S. Shin, 2004. Coordination risk and the price of debt, European Economic Review 48, 1: 133-153.

Morris, S. and H. S. Shin, 2001. Rethinking multiple equilibria in macroeconomic modeling, NBER Macroeconomics Annual 2000, 15: 139-161.

Mollick, E. 2014. The dynamics of crowdfunding: An exploratory study. Journal of Business Venturing, 29 1: 1-16.

Peia O. and R. Vranceanu, 2017. The cost of capital in a model of financial intermediation with coordination frictions, Oxford Economic Papers, doi.org/10.1093/oep/gpx037

Strausz, R. A., 2017. A theory of crowdfunding: A mechanism design approach with demand uncertainty and moral hazard, American Economic Review 107, 6: 1430-1476.

Veldkamp, L. L., 2011. Information Choice in Macroeconomics and Finance. Princeton University Press.

\section{Appendix : Calculations}

\subsection{The equilibrium solution}

Recall Equations (6) and (8):

$$
\begin{aligned}
{\left[\left(x^{*}+\epsilon\right)-\theta^{*}\right]\left[\left(x^{*}+\epsilon\right)+\theta^{*}-2 \rho\right] } & =4 \epsilon r \\
\left(x^{*}-\theta^{*}\right) & =\omega+\epsilon(1-2 v)
\end{aligned}
$$

We replace $\left(x^{*}-\theta^{*}\right)=\omega+\epsilon(1-2 v)$ in the former:

$$
\begin{aligned}
{[\omega+2 \epsilon(1-v)]\left[\left(x^{*}+\epsilon\right)+\theta^{*}-2 \rho\right] } & =4 \epsilon r \\
{\left[\left(x^{*}+\epsilon\right)+\theta^{*}-2 \rho\right] } & =\frac{4 \epsilon r}{[\omega+2 \epsilon(1-v)]} \\
x^{*}+\theta^{*} & =\frac{4 \epsilon r}{[\omega+2 \epsilon(1-v)]}-\epsilon+2 \rho
\end{aligned}
$$


Thus:

$$
\begin{aligned}
x^{*}-\theta^{*} & =\omega+\epsilon(1-2 v) \\
x^{*}+\theta^{*} & =\frac{4 \epsilon r}{[\omega+2 \epsilon(1-v)]}-\epsilon+2 \rho
\end{aligned}
$$

The sum of the two equations leads to:

$$
\begin{aligned}
2 x^{*} & =\frac{4 \epsilon r}{[\omega+2 \epsilon(1-v)]}-\epsilon+2 \rho+\omega+\epsilon(1-2 v) \\
x^{*} & =\frac{2 \epsilon r}{[\omega+2 \epsilon(1-v)]}+\rho+0.5 \omega-\epsilon v \\
\theta^{*} & =x^{*}-\omega-\epsilon(1-2 v) \\
& =\frac{2 \epsilon r}{[\omega+2 \epsilon(1-v)]}+\rho-0.5 \omega-\epsilon(1-v)
\end{aligned}
$$

\subsection{The financial efficiency condition}

All projects are financially efficient if:

$$
\begin{aligned}
\left(\theta^{*}-\rho\right) & >r \\
\frac{2 \epsilon r}{[\omega+2 \epsilon(1-v)]}+\rho-0.5 \omega-\epsilon(1-v) & >r+\rho \\
\frac{2 \epsilon r}{[\omega+2 \epsilon(1-v)]}-0.5 \omega-\epsilon(1-v) & >r \\
\frac{4 \epsilon r}{[\omega+2 \epsilon(1-v)]}-2 r & >\omega+2 \epsilon(1-v) \\
4 \epsilon r-2 r[\omega+2 \epsilon(1-v)] & >[\omega+2 \epsilon(1-v)]^{2} \\
2 r[2 \epsilon-\omega-2 \epsilon(1-v)] & >[\omega+2 \epsilon(1-v)]^{2} \\
2 r(2 \epsilon v-\omega) & >[\omega+2 \epsilon(1-v)]^{2}
\end{aligned}
$$

And, in the opposite case, some inefficient project can be implemented if:

$$
H=[\omega+2 \epsilon(1-v)]^{2}-2 r(2 \epsilon v-\omega)>0
$$

The function $H=H(\omega)$ is a convex parable. 


$$
\begin{aligned}
H(\omega) & =[\omega+2 \epsilon(1-v)]^{2}-2 r(2 \epsilon v-\omega) \\
& =\omega^{2}+4 \omega \epsilon(1-v)+4[\epsilon(1-v)]^{2}-4 r \epsilon v+2 r \omega \\
& =\omega^{2}+2 \omega[2 \epsilon(1-v)+r]+4[\epsilon(1-v)]^{2}-4 r \epsilon v
\end{aligned}
$$

To determine the solutions to $H(\omega)=0$, we calculate the (half) discriminant:

$$
\begin{aligned}
\Delta & =[2 \epsilon(1-v)+r]^{2}-4\left([\epsilon(1-v)]^{2}-r \epsilon v\right) \\
& =[2 \epsilon(1-v)+r]^{2}-4[\epsilon(1-v)]^{2}+4 r \epsilon v \\
& =4[\epsilon(1-v)]^{2}+4 r \epsilon(1-v)+r^{2}-4[\epsilon(1-v)]^{2}+4 r \epsilon v \\
& =4 r \epsilon(1-v)+r^{2}+4 r \epsilon v \\
& =4 r \epsilon+r^{2}
\end{aligned}
$$

The roots of $H(\omega)=0$ are thus:

$$
\omega_{1,2}=-[2 \epsilon(1-v)+r] \pm \sqrt{4 r \epsilon+r^{2}} .
$$

\subsection{The expected profit}

$$
\Pi=\rho \int_{\theta^{*}(\rho)}^{Z} l\left(\theta, x^{*}(\rho)\right) d F(\theta)
$$

As it has been previously shown (equations 4 and 3), for any $\theta$, the frequency of investors is given by:

$$
l\left(\theta, x^{*}\right)=(1-\gamma) \frac{1}{2 \epsilon}\left[\theta+\epsilon-x^{*}\right]+\gamma \frac{1}{2 \epsilon}\left[\theta+\epsilon+\mu-x^{*}\right]=\frac{1}{2 \epsilon}\left[\theta+\epsilon-x^{*}+\omega\right]
$$

where now $x^{*}=x^{*}(\rho)$ according to equation (9). 
The expected profit becomes:

$$
\begin{aligned}
\Pi & =\rho \int_{\theta^{*}}^{Z} \frac{1}{2 \epsilon}\left[\theta+\epsilon-x^{*}+\omega\right] d F(\theta) \\
& =\frac{\rho}{2 Z \epsilon}\left[0.5 \theta^{2}+\left(\epsilon-x^{*}+\omega\right) \theta\right]_{\theta^{*}}^{Z} \\
& =\frac{\rho}{2 Z \epsilon}\left[\left(\epsilon-x^{*}+\omega+0.5 Z+0.5 \theta^{*}\right)\left(Z-\theta^{*}\right)\right]
\end{aligned}
$$

According to Eq. (6), we know that $\left(x^{*}-\theta^{*}\right)=\omega+\epsilon(1-2 v)$, thus $-x^{*}+\omega+\epsilon=-\theta^{*}+2 \epsilon v$.

The expected profit becomes:

$$
\Pi=\frac{\rho\left[0.5\left(Z-\theta^{*}\right)+2 \epsilon v\right]\left(Z-\theta^{*}\right)}{2 Z \epsilon}
$$

Our problem is defined only for $\theta^{*}<Z$.

Remember the equilibrium definition of $\theta^{*}$ in Eq. (10), $\theta^{*}=\frac{2 \epsilon r}{[\omega+2 \epsilon(1-v)]}+\rho-0.5 \omega-$ $\epsilon(1-v)$. We have $Z-\theta^{*}=Z-\frac{2 \epsilon r}{[\omega+2 \epsilon(1-v)]}-\rho+0.5 \omega+\epsilon(1-v)$. Denoting by:

$$
a=Z-\frac{2 \epsilon r}{[\omega+2 \epsilon(1-v)]}+0.5 \omega+\epsilon(1-v)>0
$$

we obtain $\left(Z-\theta^{*}\right)=(a-\rho)$. The expected profit can be written as:

$$
\Pi(\rho)=(2 Z \epsilon)^{-1} \rho[0.5(a-\rho)+2 \epsilon v](a-\rho) .
$$

This is a polynomial of the third degree.

$\Pi(\rho)=0$ has three solutions: $\rho_{1}=0, \rho_{2}=a, \rho_{3}=a+4 \epsilon v$, with $\rho_{1}<\rho_{2}<\rho_{3}$.

Figure 1 presents the plot of the expected profit depending on $\rho$. (Parameters are $Z=$ $2, \epsilon=0.10, \omega=0.025, v=0.5, r=0.25):$ 


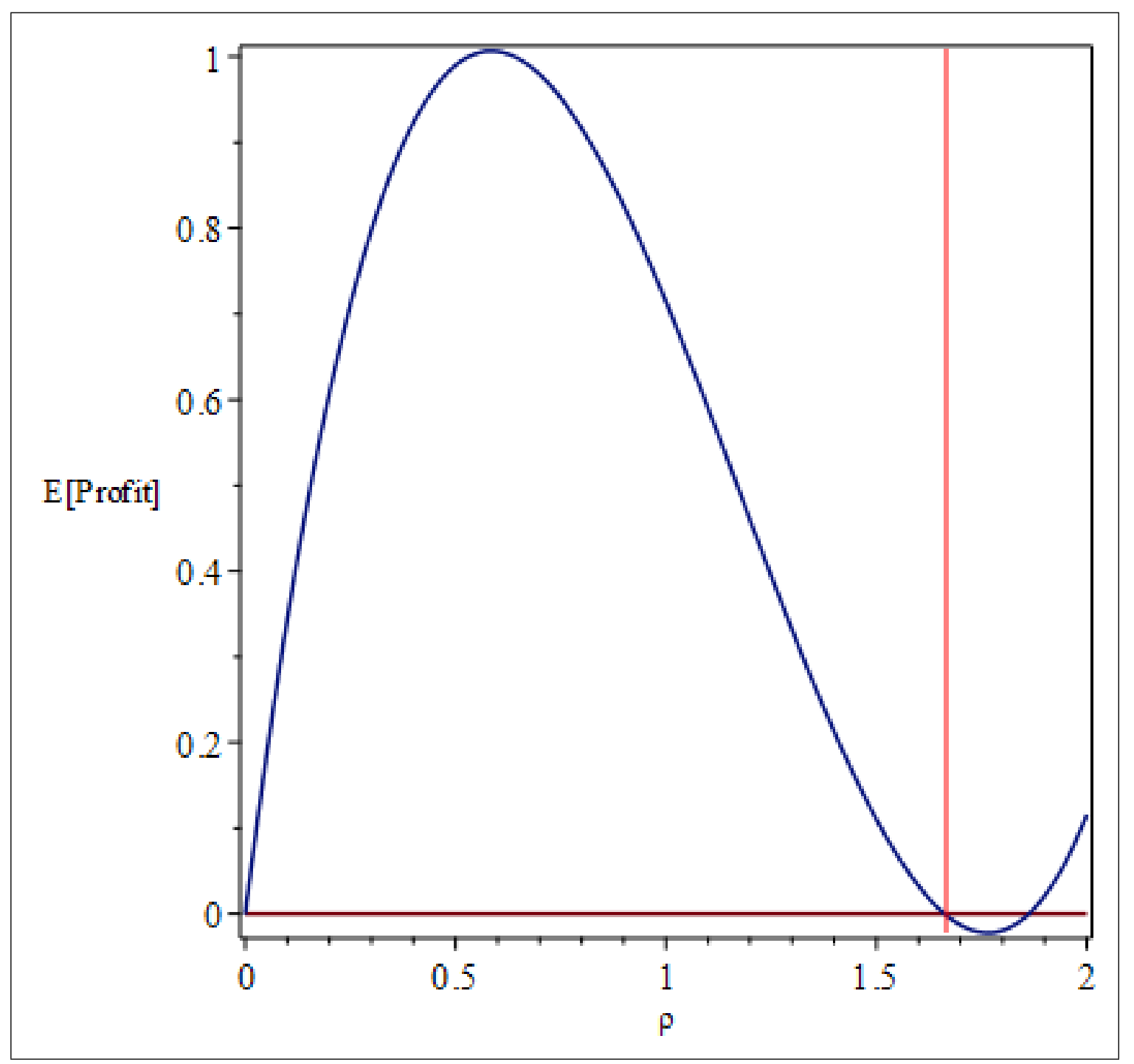

\subsection{The maximum of the expected profit}

The derivative of the profit function is:

$$
\begin{aligned}
(2 Z \epsilon) \frac{d \Pi}{d \rho} & =[0.5(a-\rho)+2 \epsilon v](a-\rho)-0.5 \rho(a-\rho)-\rho[0.5(a-\rho)+2 \epsilon v] \\
& =0.5(a-\rho)^{2}+2 \epsilon v(a-\rho)-0.5 \rho(a-\rho)-0.5 \rho(a-\rho)-2 \rho \epsilon v \\
& =0.5(a-\rho)^{2}+2 \epsilon v(a-\rho)-\rho(a-\rho)-2 \rho \epsilon v \\
& =0.5(a-\rho)^{2}+2 \epsilon v a-\rho(a-\rho)-4 \rho \epsilon v \\
& =0.5 a^{2}-a \rho+0.5 \rho^{2}+2 \epsilon v a-\rho a+\rho^{2}-4 \rho \epsilon v \\
& =1.5 \rho^{2}-2 \rho(a+2 \epsilon v)+0.5 a^{2}+2 \epsilon v a
\end{aligned}
$$


It turns out that $\left[\frac{d \Pi}{d \rho}\right]_{\rho=0}>0$.

The first order condion for profit maximization $\frac{d \Pi}{d \rho}=0$ leads to:

$$
\hat{\rho}_{1,2}=\frac{2}{3}\left[(a+2 \epsilon v) \pm \sqrt{(0.5 a+2 \epsilon v)^{2}-\epsilon v a}\right]
$$

The first root, $\hat{\rho}_{1} \in\left[0, \rho_{2}\right]$ corresponds to a local maxiumum of the profit function, the second root, $\hat{\rho}_{2} \in\left[\rho_{2}, \rho_{3}\right]$ corresponds to a local minimum.

Our problem is not defined for $\rho>\rho_{2}$, thus the local maxium is the only maximum.

\subsection{Overenthousiasm and the platform fee}

Recall the definition: $a=Z-\frac{2 \epsilon r}{[\omega+2 \epsilon(1-v)]}+0.5 \omega+\epsilon(1-v)$. The derivative of $a$ with respect to $\omega$ is positive:

$$
\frac{d a}{d \omega}=\frac{2 \epsilon r}{[\omega+2 \epsilon(1-v)]^{2}}+\frac{1}{2}>0
$$

Then recall the definition of the optimal tax:

$$
\begin{gathered}
\hat{\rho}=\frac{2}{3}\left[(a+2 \epsilon v)-\sqrt{(0.5 a+2 \epsilon v)^{2}-\epsilon v a}\right] \\
\frac{d \hat{\rho}}{d \omega}=\frac{2}{3}\left[\frac{d a}{d \omega}-\frac{1}{2}\left[(0.5 a+2 \epsilon v)^{2}-\epsilon v a\right]^{-1 / 2}[(0.5 a+2 \epsilon v)-\epsilon v] \frac{d a}{d \omega}\right] \\
=\frac{2}{3} \frac{d a}{d \omega}\left[1-\frac{1}{2}\left[(0.5 a+2 \epsilon v)^{2}-\epsilon v a\right]^{-1 / 2}(0.5 a+\epsilon v)\right]
\end{gathered}
$$


As $\frac{d a}{d \omega}>0$,

$$
\begin{aligned}
\frac{d \hat{\rho}}{d \omega} & >0 \Leftrightarrow\left[1-\frac{1}{2}\left[(0.5 a+2 \epsilon v)^{2}-\epsilon v a\right]^{-1 / 2}(0.5 a+\epsilon v)\right]>0 \\
& \Leftrightarrow 2\left[(0.5 a+2 \epsilon v)^{2}-\epsilon v a\right]^{1 / 2}>(0.5 a+\epsilon v) \\
& \Leftrightarrow 4(0.5 a+2 \epsilon v)^{2}-(0.5 a+\epsilon v)^{2}-4 \epsilon v a>0 \\
& \Leftrightarrow((a+4 \epsilon v)-(0.5 a+\epsilon v))((a+4 \epsilon v)+(0.5 a+\epsilon v))-4 \epsilon v a>0 \\
& \Leftrightarrow(0.5 a+3 \epsilon v)(1.5 a+5)-4 \epsilon v a>0 \\
& \Leftrightarrow 0.75 a^{2}+2.5 \epsilon v a+4.5 \epsilon v a+15(\epsilon v)^{2}-4 \epsilon v a>0 \\
& \Leftrightarrow 0.75 a^{2}+3 \epsilon v a+15(\epsilon v)^{2}>0 \\
& \Leftrightarrow a^{2}+4 \epsilon v a+20(\epsilon v)^{2}>0
\end{aligned}
$$




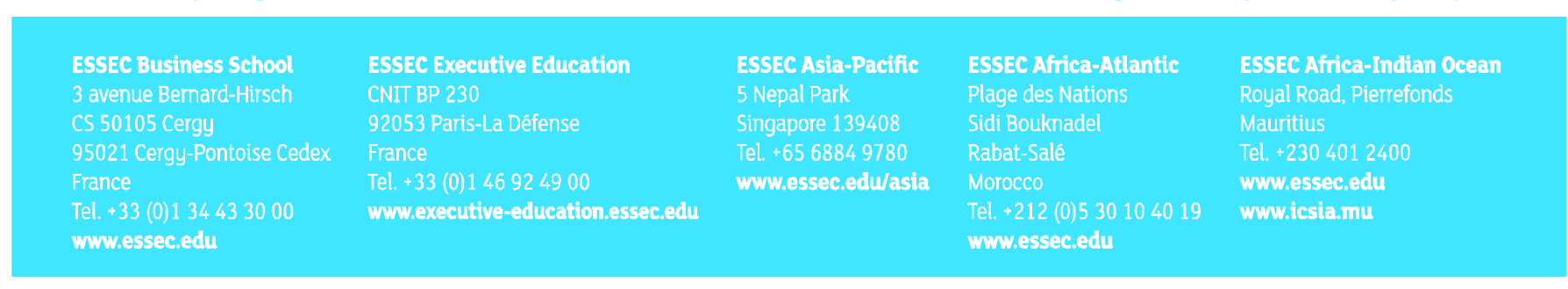

\section{Contacts}

Centre de Recherche

+33 (0)1344330 91

research.center@essec.fr 